\title{
Interculturalidade e comunicação nas organizações: reflexões antropológicas e notas para uma agenda de pesquisas
}

Interculturality and communication in the organizations: anthropological reflections and notes for an agenda of research efforts

Interculturalidad y comunicación en las organizaciones: reflexiones antropológicas y notas para una agenda de investigaciones

(9) Pedro Jaime de Coelho Júnior

- Doutor em Antropologia Social pela Universidade de São Paulo (USP) e em Sociologia e Antropologia pela Université Lumière Lyon 2

- Mestre em Antropologia Social pela Universidade Estadual de Campinas (Unicamp), Graduado em Administração pela Universidade Federal de Bahia (UFBA)

- Professor do Programa de Mestrado e Doutorado em Administração do Centro Universitário da Fundação Educacional Inaciana (FEI)

- Professor dos cursos de Graduação em Administração e em Comunicação da Escola Superior de Propaganda e Marketing (ESPM-SP)

- Autor de artigos em revistas científicas de Ciências Sociais e de Administração e de capítulos de livros publicados nestas áreas

- Email: pedrojaime@fei.edu.br 


\section{Resumo}

Proponho neste artigo uma reflexão sobre o debate antropológico contemporâneo em torno do conceito de cultura, assim como da ideia de diversidade. 0 propósito dessa reflexão é extrair, da mirada da antropologia para essas questões, contribuições que possam fertilizar a pesquisa sobre interculturalidade e comunicação nas organizações

PALVRAS-CHAVE: COMUNICAÇÃO・ORGANIZAÇÕES・ANTROPOLOGIA・INTERCULTURALIDADE.

\section{Abstract}

I propose in this article a reflection on the contemporary anthropological debate on the concept of culture, as well as the idea of diversity. The purpose of this reflection is to extract, from the anthropological perspective on these issues, contributions that can fertilize the research on intercultural communication in organizations.

KEYEWORDS: COMMUNICATION・ORGANIZATIONS・ANTHROPOLOGY・INTERCULTURALITY.

\section{Resumen}

Propongo con este artículo una reflexión sobre el debate antropológico contemporáneo en torno al concepto de cultura, así como a la idea de la diversidad. El propósito de esta reflexión es extraer, de la mirada de la antropología para estas cuestiones, contribuciones que puedan fertilizar las investigaciones sobre la interculturalidad y la comunicación en las organizaciones. 
$\mathrm{N}$

o ano passado, minha esposa e eu recebemos em São Paulo a visita de um casal de estrangeiros, amigos que fizemos por ocasião da nossa estadia na França, em 2009 e 2010. Os dois membros do casal são pessoas a quem a teoria antropológica contemporânea considera como tendo suas experiências sociais construídas in-between cultures (AbuLughod, 1991). Ele, Luca Sadurni, italiano da região de Nápoles, vivendo atualmente em Lyon na França. Ela, Andra Promenu, romena de Bucareste, que reside igualmente em Lyon. Durante o tempo em que passaram conosco, fizemos um passeio pela feira livre da Vila Madalena. Eles ficaram encantados com as cores, os cheiros e os sabores das frutas comercializadas ali. Luca, um tipo apaixonado pela arte de cozinhar, estava especialmente atento a cada textura, a cada aroma.

De passagem por uma banca de condimentos, cuja proprietária fazia diversos mixes com distintos ingredientes, tateando 0 português arriscou uma pergunta à simpática feirante: "Qual desses temperos é tipicamente brasileiro?" Sua interlocutora não hesitou e de pronto respondeu com uma pitada de ironia: "Tudo aqui é brasileiro, pois sou eu que faço".

Estava diante de um encontro intercultural e na volta para casa fiquei refletindo, juntamente com meus amigos, que aquele breve diálogo evidenciava duas concepções de cultura. A primeira, que chamarei de tradicional, liga uma cultura a um povo e um território. Finalmente deveria haver o tempero genuinamente associado ao povo brasileiro! A segunda, que designarei como contemporânea, pensa a cultura como fluxo e, rejeitando concepções de pureza, integra a mistura, o hibridismo como processos característicos da construção cultural.

Tomarei essa anedota extraída da vida cotidiana como ponto de partida para a escrita de um ensaio sobre interculturalidade e comunicação nas organizações. 0 texto que segue está dividido em três seções. Inicialmente, reviso brevemente o debate antropológico contemporâneo sobre o conceito de cultura. Em seguida faço o mesmo com a ideia de diversidade. Por fim, busco sinalizar para a contribuição que a mirada da antropologia para a cultura e a diversidade pode oferecer para fertilizar as pesquisas sobre interculturalidade e comunicação nas organizações.

\section{CULTURA: UM CONCEITO SOB RASURA NO CAMPO DA ANTROPOLOGIA}

0 conceito de cultura tem sido alvo de um intenso debate antropológico desde o início dos anos 1990. Atacada por uns, que afirmam escrever contra a cultura (Abu-Lughod 1991), ou propõem abandonar de vez essa palavra hiperreferencial (Kuper, 2002), defendida por outros, que advogam a ideia de que a cultura não é um objeto em vias de extinção (Sahlins, 1997a, 1997b), a cultura tem sido fortemente problematizada na antropologia. Da forma como vejo as coisas, o debate revela justamente a centralidade que o conceito ainda possui no campo antropológico. Estou pensando aqui em uma reflexão de Mikhail Bakhtin. Em Marxismo e filosofia da linguagem, Bakhtin (2004) afirma que o signo, quando subtraído das tensões da luta social, debilitase infalivelmente, degenerando em alegoria, tornando-se objeto de estudo dos filólogos, deixando de ser um instrumento racional e vivo para a sociedade. Com essa afirmação, queria destacar que, quando as palavras estão "vivas", elas são objeto de disputas em torno do seu sentido, o que não acontece quando se cristalizam em torno de significados fixos, dicionarizados. Ademais, como bem ressalta Terry Eagleton (2005, p. 60), "é perigoso afirmar que a idéia de cultura está em perigo hoje em dia, pois quando é que ela não esteve?". Enfim, penso que as discussões em torno do conceito de cultura configuram-se como um endless debate, para tomar emprestada a expressão de Nomi Maya (2001). 
Não tenho pretensões aqui de recuperar esse debate em sua larga complexidade. Partindo da compreensão de que todas as visões são parciais, à medida que somos sempre autores posicionados, escrevendo a partir de um lugar (Clifford, 1991; Barth, 2000), afirmo a minha concordância com a perspectiva de Sahlins (1997a, p. 41). Para ele, abandonar a cultura como um conceito antropológico central, sob o argumento de que está manchado por um passado duvidoso, seria uma espécie de "suicídio epistemológico". Deixar-se-ia de compreender o fenômeno único que a ideia de cultura nomeia e distingue: a organização da experiência e da ação humanas por meios simbólicos. Ou ainda com a advertência de Ulf Hannerz (1998, p. 64-65), para quem, "para sermos capazes de reconhecer a contradição e os mal-entendidos, não deveríamos ter que escrever contra a cultura". Ele acrescenta que, do seu ponto de vista, a cultura "continua sendo a palavra-chave mais útil que temos para mapear essa capacidade peculiar dos seres humanos para criar e manter suas próprias vidas conjuntamente" (Hannerz, 1998, p. 74).

Nessa linha de raciocínio, penso ser mais interessante fazermos com o conceito de cultura algo que Stuart Hall (2000) propõe para o conceito de identidade. Não considerá-la como um conceito inadequado, que deve ser substituído por outros supostamente mais verdadeiros, ou que aspiram à produção de um conhecimento positivo. Mas colocá-la sob rasura, atentando para o fato de que não servem mais em sua forma original. Todavia, de maneira renovada, é não apenas possível, mas inevitável, continuar a pensar com ele. Sendo assim, o meu esforço nas próximas linhas deixará de fora as reflexões de autores que empreendem desconstruções do conceito de cultura, estando dirigido para a apresentação dos argumentos de alguns daqueles que propõem uma redefinição do mesmo.

0 primeiro aspecto que gostaria de apontar quanto à redefinição do conceito de cultura diz respeito ao questionamento do pressuposto de homogeneidade que estaria a ele associado. Quanto a isso, Fredrik Barth (2000) por exemplo afirma que a premissa holista e integrada da cultura pode resultar numa visão monocromática da realidade e, portanto, numa cegueira quando da interpretação das complexas realidades com as quais o etnógrafo se defronta durante o trabalho de campo. Ele adverte que durante muito tempo os antropólogos foram treinados para suprimir os sinais de incoerência e de multiculturalismo encontrados nessas realidades. Em vez de tentarem fazer com que suas teorias dessem conta do que é efetivamente encontrado durante a etnografia, acabavam sendo levados a escolher algum padrão claro e delimitado em meio ao cenário confuso.

Renato Rosaldo (1993) sinaliza para questões bastante próximas. Para ele, a cultura, que fora entendida por Ruth Benedict (1984) como um padrão de normas que orientam o comportamento, ou por Clifford Geertz (1989) como um sistema de símbolos ou como uma estrutura de significados, vem sofrendo um importante processo de politização. Dessa forma, não é mais convincente o argumento de que a cultura é partilhada por todos os membros de uma dada sociedade. A noção de cultura como significados compartilhados, sugere Rosaldo, dificultou o estudo das zonas de diferença dentro de e entre culturas. Ele destaca, então, que harmonia e consenso têm sido substituídos, na reflexão sobre a cultura, por mudança, inconsistência e contradições. Ressalta ainda que as questões de desigualdade e conflito se tornaram urgentes no debate antropológico, fazendo com que as bordas da cultura deixassem a condição de exceção, de lugar marginal, como eram vistas na perspectiva clássica, para ganhar centralidade.

Esse argumento está presente também na reavaliação do conceito empreendida por Ulf Hannerz (1992). Segundo ele, as caracterizações da cultura a partir de ideias como ordenação, harmonia e equilíbrio durável são todas questionáveis. Retomando uma clássica premissa antropológica, adverte que quando o antropólogo afirma captar o ponto de vista do nativo dever-se-ia perguntar: qual nativo? Dialogando com Clifford Geertz (1989), para quem o etnógrafo interpreta uma cultura olhando-a por sobre os ombros do nativo, Hannerz sugere que o que o antropólogo enxerga depende da visão da pessoa sobre cujo ombro está 
mirando. Esse ponto é justamente o foco da advertência de Barth (2000, p. 136) de que "não há como encontrar o verdadeiro informante, aquele que nos dirá o que tudo aquilo realmente significa". Hannerz (1992) destaca também que a ideia da cultura como algo compartilhado está baseada numa tendência enraizada na antropologia de pensá-la como análoga à língua. Se a língua para fazer seu trabalho precisava ser partilhada, o mesmo deveria acontecer com a cultura. Todavia, os debates contemporâneos no âmbito da filosofia da linguagem, da linguística e da teoria literária já evidenciaram o caráter dinâmico e conflitual da língua, o que fica patente no uso de expressões como jogos de linguagem. Consequentemente, seria de se esperar uma reavaliação na compreensão da cultura.

É dentro desse marco que podemos entender a afirmação de Clifford (1998), para quem, assim como uma língua é a interação e a luta de dialetos regionais, de jargões profissionais, da fala de diferentes grupos etários etc., uma cultura é, concretamente, um diálogo em aberto, criativo, de subculturas, de membros e não-membros, de diversas facções. Ou a de Roger Keesing (1987) e a de Barth (2000), em referências também claras à Clifford Geertz, que sugeriu que a cultura fosse pensada a partir da metáfora textual. Ela seria como um texto que os indivíduos leem para interpretar suas vidas. Keesing afirma que a cultura, como os textos, é diferencialmente lida por homens e mulheres, jovens e velhos, especialistas e não-especialistas. Barth, por sua vez, ressalvando que considera a metáfora inadequada, aponta que, para produzir o texto cultural é preciso mapear os vários agentes, cada um com diferentes interesses, capacidades e concepções divergentes sobre os significados dos eventos.

Essa abertura para a descontinuidade na análise cultural caminha em paralelo com a reabilitação do sujeito, da capacidade de agência dos atores sociais, no âmbito da interpretação antropológica. Assim, de acordo com Hannerz (1998) não se pode considerar a individualidade como uma coisa residual, algo que fica fora dos domínios da cultura. Da mesma forma, Barth (2000) afirma que, para descobrir significados no mundo dos outros, ao contrário do que pregou boa parte da teoria antropológica moderna, de Claude Lévi-Strauss a Clifford Geertz, é necessário ligar um fragmento de cultura e um(a) determinado(a) ator (atriz) à constelação particular de experiências, conhecimentos e orientações desse ator/dessa atriz. Para ele, é preciso incorporar na análise da cultura uma visão dinâmica da experiência como resultado da interpretação dos eventos por indivíduos. Isto porque "varia imensamente o que é visto e ouvido, e a maneira como a mensagem toca a cada uma das pessoas" (Barth, 2000, p. 134).

Em suma, a cultura tem sido relacionada com a estrutura social, uma vez que os significados e as formas simbólicas são gerados por tipos particulares de relações sociais. Com bem adverte Ulf Hannerz (1992), se a cultura é entendida como um fenômeno coletivo, a sua compreensão demanda uma sociologia. Nesse movimento de aproximação entre cultura e sociedade, a análise cultural se encontra também com a política. Quanto a esse aspecto, cabe levar em conta na interpretação antropológica os múltiplos discursos que muito frequentemente coexistem em um campo dinâmico de interações e conflitos (Ortner et al., 1994). Esse é o ponto que Eric Wolf (2003, p. 337) sublinha, quando ressalta que "o poder está implicado no significado por seu papel na sustentação de uma versão de significação como verdadeira".

Sendo assim, a cultura, como experiência vivida, está continuamente em construção, desconstrução e reconstrução, sob o impacto de processos econômicos, sociais e políticos; e, portanto, o conceito antropológico de cultura, renovado e expurgado de seus vícios de origem, deve ser capaz de dar conta da complexidade desse processo. Só assim poderá contribuir para 0 entendimento da diversidade humana, pensada não apenas entre culturas, mas dentro de cada uma delas. Diversidade é justamente outra ideia-chave da antropologia. A seguir recupero também alguns argumentos que caracterizam o debate antropológico contemporâneo em torno desse conceito. 


\section{DIVERSIDADE: RIQUEZA DA HUMANIDADE E MARCA REGISTADA DA ANTROPOLOGIA}

Em um texto curiosamente denominado Diversity is our business, o antropólogo sueco Ulf Hannerz (2010) argumentou que a comunidade antropológica não deve aceitar passivamente a tendência fortemente estabelecida em alguns discursos públicos que tomam a diversidade como algo autoevidente, bom e valioso, sem problematizá-la. Mas o que significa problematizar a diversidade? De que forma é possível escapar a sua compreensão como algo autoevidente? 0 que alguns dos antropólogos que trataram mais diretamente dessa questão podem nos dizer?

Numa conferência originalmente proferida na Unesco em 1952, num contexto pós-Segunda Guerra Mundial, marcado pelos horrores cometidos em nome da raça pelo nazismo alemão, Claude Lévi-Strauss (1993) destacou que a vida da humanidade não se desenvolve por um regime de monotonia uniforme, mas sim por meio de modos extraordinariamente diversificados de sociedades e civilizações. Ele sinalizou para a complexidade envolvida nesse processo. "É indubitável que os homens elaboraram culturas diferentes por causa do afastamento geográfico, das propriedades particulares do meio e da ignorância que tinham do resto da humanidade", aponta. Mas logo acrescenta que isso só seria rigorosamente verdadeiro "se cada cultura ou cada sociedade tivesse nascido e se desenvolvido isoladamente de todas as outras", o que, "não é nunca o caso, à exceção talvez de exemplos raros" (Lévi-Strauss, 1993, p. 332). Assim, adverte que ao lado das diferenças originárias do isolamento, existem aquelas, consideradas também muito importantes, "devidas à proximidade: desejo de se oporem, de se distinguirem, de serem elas mesmas". Ademais, complementa enfatizando que a diversidade existe também no interior de cada sociedade, "em todos os grupos que a constituem". Sendo assim, "a diversidade das culturas humanas", sentencia, "é menos função do isolamento dos grupos que das relações que os unem" (Lévi-Strauss, 1993, p. 333).

Lévi-Strauss (1993, p. 359) é explícito sobre a imbricação das culturas humanas, marca da nossa diversidade, ao afirmar que "as formas mais cumulativas de história (...) jamais foram obra de culturas isoladas". Ao contrário, foram o resultado de culturas que, por meios variados (migrações, empréstimos, trocas comerciais, guerras), estabeleceram, voluntaria ou involuntariamente, novas combinações. Sendo assim,

a chance que uma cultura tem de totalizar esse conjunto complexo de invenções de todas as ordens, que denominamos uma civilização, é função do número e da diversidade das culturas com as quais participa na elaboração - a maior parte das vezes involuntária - de uma estratégia comum" (Lévi-Strauss, 1993, p. 359).

0 autor exemplifica: "A Europa dos primórdios do Renascimento era o lugar do encontro e da fusão das mais diversas influências: as tradições grega, romana, germânica e anglo-saxônica; as influências árabe e chinesa" (Lévi-Strauss, 1993, p 360). Em síntese, para Lévi-Strauss (1993, p. 361), "não há sociedade cumulativa em si e por si". Isso porque a história cumulativa não é propriedade de certas culturas que se distinguiriam das outras. Ela exprime "certa modalidade de existência das culturas", "sua maneira de ser conjunta".

Mas isso leva ao seguinte paradoxo: "para progredir é preciso que os homens colaborem; e, no decorrer dessa colaboração, eles vêem identificar-se gradualmente as contribuições, cuja diferença inicial era precisamente o que tornava sua colaboração fecunda e necessária" (Lévi-Strauss, 1993, p. 365). Em outras palavras, e para os fins desse texto, o encontro intercultural é fundamental para dinamizar a diversidade humana, mas ele pode ao mesmo tempo levarà homogeneidade. Numa passagem que, 
de maneira muito interessante, parece tão apropriada para pensar o atual cenário de globalização, ele afirma que "existem nas sociedades humanas, simultaneamente em elaboração, forças trabalhando em direções opostas: umas tendem à manutenção, e mesmo à acentuação de particularismos; as outras agem no sentido da convergência e da afinidade". Dito de outra forma, "a humanidade está continuamente às voltas com dois processos contraditórios". Um "tende a instaurar a unificação", ao passo que o outro "visa manter ou restabelecer a diversificação" (Lévi-Straus, 1993, p. 366). E, mesmo que essa contradição seja insolúvel, adverte Lévi-Strauss, a humanidadedevem reassumir sempre o compromisso de evitar um particularismo cego, jamais esquecendo que nenhuma sociedade dispõe de fórmulas aplicáveis, sem mediações, a todas as demais. Isto seria reduzir a humanidade a um gênero de vida único, que corresponderia a uma humanidade petrificada. Com essa ressalva em mente, ressalta ele, pode-se acreditar que a diversidade das culturas não está apenas atrás de nós, como uma marca do nosso passado. Ela está também à nossa volta, como sinal do nosso tempo; e à nossa frente, como um programa sempre renovado.

Pode-se dizer, a partir desse texto, que Lévi-Strauss defendia vigorosamente as virtudes da comunicação intercultural. Acontece que em 1971, quase vinte anos mais tarde, o antropólogo francês voltou à Unesco para proferir a palestra "Raça e cultura", na inauguração do Ano Internacional de Luta contra o Racismo. Nessa oportunidade ponderou que, "talvez devido à idade" e "certamente" em razão das "reflexões suscitadas pelo espetáculo do mundo", considerou adequado relativizar suas convicções apresentadas no texto anterior e então se expressar com franqueza (Lévi-Strauss, 1986, p. 14). Suas reflexões causaram polêmica. Advertindo que o racismo é uma doutrina que pretende ver nas características intelectuais e morais atribuídas a um conjunto de indivíduos o efeito de um patrimônio genético comum, Lévi-Strauss (1986, p. 15) afirma no novo texto que "não se pode alinhar sob essa mesma rubrica, ou imputar automaticamente ao mesmo preconceito, a atitude de indivíduos ou de grupos cuja fidelidade a determinados valores os torna parcial ou totalmente insensíveis a outros valores". De fato, não se pode. Racismo e etnocentrismo são comportamentos distintos. Se o racismo é uma forma de etnocentrismo, nem toda postura etnocêntrica caracteriza-se como racista. Mas Lévi-Strauss (1986, p. 15) prossegue advogando que esses indivíduos ou grupos

não têm culpa alguma de que se ponha uma maneira de viver ou de pensar acima de todas as outras, nem que sinta pouca atração relativamente a estes ou aqueles cujo modo de viver, respeitável em si mesmo, se afasta demasiado daquele a que se está tradicionalmente apegado.

Adverte que considera claro que essa incomunicabilidade relativa não autoriza a oprimir ou destruir os valores que se rejeitam ou os seus representantes. Porém, não vê nela nada de revoltante, podendo até mesmo representar "o preço a pagar" para que cada cultura se conserve e encontre em si própria as fontes necessárias à sua renovação (Lévi-Straus, 1986, p. 15). Retomando então um argumento desenvolvido na ocasião anterior em que falou à plateia da Unesco, ressaltou que, se existe entre as sociedades humanas um certo optimum de diversidade para além do qual elas não podem existir, mas abaixo do qual elas também não podem descer sem perigo, deve-se reconhecer que "esta diversidade resulta em grande parte do desejo de cada cultura de se opor àquelas que a rodeiam, de se distinguir delas, numa palavra, de ser ela mesma". "Elas não se ignoram, apropriam-se de coisas umas das outras sempre que há ocasião", reconhece. Mas acrescenta que, "para que não pereçam", é necessário que "persista entre elas uma certa impermeabilidade". Sintetiza afirmando que, dessa maneira, convidava os ouvintes a

duvidarem com sabedoria, com melancolia se assim o quisessem, do futuro de um mundo em que as culturas, presas por uma paixão recíproca, já não aspirariam mais do que a celebrar-se mutuamente, numa confusão em que cada uma perderia o atrativo que poderia ter para as outras, e as suas próprias razões de existir" (Lévi-Strauss, 1986, p. 15-16).

É verdade que no texto anterior, Lévi-Strauss (1993) argumentou sabiamente que o etnocentrismo é umas das mais antigas atitudes humanas, possuindo fundamentos psicológicos sólidos, tendendo a reaparecer em cada um de nós quando nos 
encontramos numa situação inesperada. Trata-se de "repudiar pura e simplesmente as formas culturais: morais, religiosas, sociais, estéticas, que são as mais afastadas daquelas com as quais nos identificamos" (Lévi-Strauss, 1993, p. 333). Ele utiliza uma metáfora retirada da teoria da relatividade para ilustrar o seu argumento. A fim de provar que a dimensão e velocidade de deslocamento dos corpos não são valores absolutos, mas função da posição do observador, tal teoria demonstrou que para um viajante sentado junto à janela de um trem, a velocidade e o comprimento dos outros trens variam conforme estes se desloquem no mesmo sentido ou em sentido contrário. Então defende que "todo membro de uma cultura é dela tão estritamente solidário como esse viajante ideal o é de seu trem". Isto porque, "desde o nosso nascimento, nosso meio faz penetrar em nós, através de mil processos conscientes e inconscientes, um sistema complexo de referências, consistindo em juízos de valor, motivações, centros de interesse". Consequentemente, nós nos deslocamos com esse sistema de referências e as realidades culturais de fora "só são observáveis através das deformações que ele lhes impõe, chegando mesmo a colocar-nos na impossibilidade de se perceber o que quer que seja" (Lévi-Strauss, 1993, p. 345). Em síntese: ele havia argumentado que o etnocentrismo é um universal humano que dificulta, talvez até mesmo impossibilita, a comunicação intercultural. Porém, da forma como entendo sua argumentação nesse texto, o desafio da humanidade seria o de renovar constantemente o compromisso de construir essa comunicação intercultural, de valorizar "certa modalidade de existência das culturas", "sua maneira de ser conjunta".

Não parece ser mais esta a aposta que faz no texto posterior. Nele, retomando a metáfora extraída da física, Lévi-Strauss (1986) afirma que as culturas se assemelham a trens que circulam mais ou menos depressa, cada um deles sobre a sua própria via e numa direção diferente. Os que viajam na mesma direção do nosso podem ser observados em seus detalhes, sendo possível perceber a fisionomia e mesmo a mímica dos viajantes. Porém, daqueles que o cruzam, dirigindo-se em sentido oposto, recebemos apenas uma "imagem confusa", que depressa se esvai, reduzindo-se a uma

mancha momentânea do nosso campo visual, que não nos dá qualquer informação sobre o próprio acontecimento e que só nos irrita, porque interrompe a contemplação plácida da paisagem que serve de pano de fundo aos nossos devaneios (Lévi-Strauss, 1986, p. 30-31).

Essa metáfora, certamente esclarecedora, mas posta nesses termos e extraída dela tais consequências, não sugeriria implicitamente uma intolerância com a diversidade, uma postura de fechamento para a comunicação intercultural?

Tenho consciência do risco que corro ao sugerir que um dos maiores expoentes da história da antropologia professou uma postura de fechamento à interculturalidade. Mas, me parece que essa via pode ser visualizada em suas próprias palavras. Ao final do seu texto, Lévi-Strauss (1986, p. 48) afirma que "é inegável que nos embalamos no sonho de que a igualdade e a fraternidade reinarão um dia entre os homens, sem que a diversidade seja comprometida". Mas, se a humanidade não quiser se resignar a tornar-se "consumidora estéril dos valores que soube criar no passado, unicamente capaz de dar à luz obras bastardas, invenções grosseiras e pueris", ela precisará reaprender que "toda verdadeira criação implica uma certa surdez ao apelo de outros valores, podendo ir até à sua recusa, senão mesmo até à sua negação". E acrescenta, argumentando que, "plenamente alcançada, a comunicação integral com o outro condena, mais tarde ou mais cedo, a originalidade da sua criação e da minha". Poderíamos perguntar: escapar à ingenuidade expressa na fraterna convivência com o outro passa necessariamente pelo fechamento em si mesmo? Essa pergunta é tanto mais necessária, se levarmos em conta que, no atual contexto das novas diásporas que se produzem num mundo cada vez mais globalizado, é comum que esse outro esteja bem mais próximo. Talvez ele esteja dentro do si mesmo, como é o caso dos indivíduos que vivem in-between cultures. Seja como for, esse risco de ver um equívoco na postura defendida por Lévi-Strauss, eu não posso corrê-lo sozinho, sem o lastro de um avalista. E o aval, eu 0 consegui em outro autor clássico, referência dos debates antropológicos contemporâneos. 
No texto Os usos da diversidade, o antropólogo estado-unidense Clifford Geertz (2001) retoma o argumento de Lévi-Strauss, segundo o qual o etnocentrismo não apenas nunca desaparecerá por completo, posto que faz parte da essência mesma da nossa espécie; como o seu enfraquecimento é perigoso, por nos deixar à mercê de uma espécie de entropia moral. Porém, ele retoma esse argumento para submetê-lo à seguinte indagação: "Será o narcisismo moral a alternativa à entropia moral?" (Geertz, 2001, p. 71). Ao responder a esse questionamento, revela seu desacordo com a perspectiva lévi-straussiana. Afirma Geertz (2001, p. 73):

Uma antropologia muito temerosa de destruir a integridade e a criatividade culturais, nossas e de todos os outros, por se aproximar de outras pessoas, conversar com elas e procurar apreendê-las em seu cotidiano e diferença, está fadada a morrer de inanição.

Ademais, acrescenta Geertz (2001, p. 74-75), o mundo social não se divide entre "um nó perspícuo, com o qual podemos ter empatia, por mais que sejamos diferentes entre nós", e "um eles enigmático, com o qual não podemos ser empáticos, por mais que defendamos até a morte seu direito de serem diferentes de nós". No mundo contemporâneo a relação eu/outro, pensada em termos culturais, se tornou bem mais complexa. Se a variedade de maneiras com que homens e mulheres tentam viver suas vidas, objeto da reflexão antropológica, "está rapidamente se suavizando num espectro mais pálido e mais estreito", como sugere Geertz (2001, p. 68); é verdade também, como ele igualmente aponta, que "as questões morais provenientes da diversidade cultural (...), as quais, se é que chegavam a surgir, surgiam sobretudo entre sociedades (...), surgem agora, cada vez mais, dentro delas". Afinal, "as fronteiras sociais e culturais têm uma coincidência cada vez menor". Na passagem a seguir, com um toque de ironia, ele destrincha o seu argumento:

Há japoneses no Brasil, turcos à margem do Main e nativos das Índias Ocidentais e Orientais encontradas nas ruas de Birmingham, num poderoso processo de baralhamento que já vem acontecendo há um bom tempo, é claro (na Bélgica, no Canadá, no Líbano, na África do Sul, e nem a Roma dos Césares era lá muito homogênea), mas que, em nossos dias, aproxima-se de proporções extremas e quase universais. Já vai longe o tempo em que a cidade norte-americana era o principal modelo de fragmentação cultural e desordem étnica; a Paris de nos ancêtres les gaulois está ficando tão poliglota e policroma quanto Manhattan, e é possível que ainda venha a ter um prefeito da África Setentrional (ou, pelo menos, assim temem muitos dos gaulois) antes que Nova York tenha um prefeito hispânico (Geertz, 2001, p. 77).

A reflexão de Geertz sobre a diversidade é marcada por uma perspectiva que aponta as diferenças culturais, sem esquecer de fazer referência aos conflitos. Ele descreve o que denomina de 0 caso do índio bêbado e da máquina de hemodiálise, para tentar extrair dele conclusões sobre o encontro intercultural. 0 caso, bem resumidamente, é o seguinte: face à escassez de equipamentos de hemodiálise, foi criado, no âmbito do programa médico de governo do sudoeste dos Estados Unidos, uma política de fila para o acesso às máquinas por parte dos pacientes que precisassem ser submetidos a diálises, com base na gravidade do problema e na ordem de chegada dos pedidos. A eficácia do tratamento dependeria de uma disciplina rigorosa do paciente em termos de dieta e outros comportamentos. Neste cenário, um índio, após ter acesso ao recurso escasso, recusouse a parar de beber ou até mesmo a controlar sua ingestão de álcool. Sua resistência pode ser condensada na seguinte postura: "sou mesmo um índio bêbado, já faz tempo que sou assim, e pretendo continuar a sê-lo enquanto vocês conseguirem me manter vivo, amarrando-me a essa máquina". Os médicos, cujos valores eram bem distintos, consideravam que o índio estava bloqueando o acesso ao aparelho por parte de pessoas em situações igualmente desesperadoras e que poderiam fazer melhor uso dele. Eles pensavam provavelmente no tipo jovem de classe média com sonho de ingressar na universidade, um perfil bem parecido com o deles. Dadas as questões de legislação, como o índio já havia recebido a aprovação para usar a máquina quando a celeuma se instalou, os médicos não conseguiram retirá-lo do tratamento e ficaram por anos aborrecidos com situação. A história só teve um desfecho com a morte do indígena (Geertz, 2001, p. 78-79). 
Geertz (2001, p. 79-82) retira dessa história algumas conclusões interessantes para pensar sobre interculturalidade e comunicação. A primeira é que as partes envolvidas "não eram representantes de totalidades sociais ensimesmadas, que se encontrassem por acaso nas fronteiras de suas crenças". Isto porque "os índios que afastam o destino através do consumo de álcool são parte tão integrante da América contemporânea quanto os médicos que o corrigem através do uso de máquinas". A segunda é que, se houve alguma falha nesse episódio, ela diz respeito à "incapacidade, por parte de ambos os lados, de aprender o que significa estar no outro e, portanto, o que significa estar no seu". Em outras palavras: "ao que parece, ninguém aprendeu muita coisa sobre si mesmo ou sobre qualquer outra pessoa nesse episódio, e absolutamente nada sobre o caráter do encontro ocorrido entre eles, exceto pelas banalidades da repugnância e da amargura". E ele diz mais: "Não é a incapacidade de as pessoas envolvidas abandonarem suas próprias convicções e adotarem as ideias de outros que faz essa historieta parecer tão profundamente deprimente". "Tampouco o é sua falta de uma regra moral desencarnada a que recorrer - o bem maior ou 0 princípio da diferença", acrescenta. "O que responde por esse sentimento depressivo é a impossibilidade de as pessoas sequer imaginarem, em meio ao mistério da diferença, como seria possível contornar uma assimetria moral perfeitamente autêntica", sentencia. E sintetiza: "O que tende a acontecer no escuro (...) é o uso da força, para garantir a conformidade aos valores dos detentores da força, ou uma tolerância vazia, que, não comprometendo nada, não modifica nada". Ou ainda, como na história que recuperou, na qual "a força não está disponível e a tolerância é desnecessária", o que se passa é "um escoamento para um fim ambíguo" (Geertz, 2001, p. 79-80). Conclui então ressaltando que "não se trata de que devamos amar uns aos outros ou morrer (...). Trata-se de que devemos conhecer uns aos outros e viver com esse conhecimento, ou terminar isolados num mundo beckettiano de solilóquios em choque" (Geertz, 2001, p. 81-82).

Fica evidente, portanto, que Geertz (2001) incorpora o conflito na sua reflexão sobre comunicação e interculturalidade. Ele ressalta que vivemos em um momento em que as culturas não podem mais ser pensadas como "unidades emolduradas, em espaços sociais com limites definidos", uma vez que "as abordagens seriamente distintas da vida estão se misturando em espaços mal definidos, espaços sociais cujos limites não têm fixidez, são irregulares e difíceis de localizar" (Geertz, 2001, p. 83). Isso certamente dá uma complexidade muito maior à compreensão e ao exercício da comunicação intercultural. E Geertz resume esse exercício destacando que não é preciso escolher; ao contrário, é preciso não escolher entre "um cosmopolitismo sem conteúdo", condensado na imagem de "um mundo repleto de pessoas tão apaixonadamente encantadas com a cultura umas das outras"; e "um provincianismo sem lágrimas", expresso na imagem de "um mundo repleto de pessoas que glorifiquem alegremente seus heróis e diabolizem seus inimigos" (Geertz, 2001, p. 84). Nenhum desses extremos, ressalta, nos ajudam na tarefa de viver na colagem cultural que marca o mundo contemporâneo. Na passagem a seguir, ele toca com perspicácia nessa equação:

Compreender aquilo que, de uma dada maneira ou forma, nos é estranho e tende a continuar a sê-lo, sem aparar suas arestas com vagos murmúrios sobre a humanidade comum, sem desarmá-lo com o indiferentismo do "a cada cabeça sua sentença", e sem descartá-lo como encantador, adorável até, mas sem importância, é uma habilidade que temos que aprender duramente e, depois de havê-la aprendido, sempre de maneira muito imperfeita, temos de trabalhar continuamente para manter viva (Geertz, 2001, p. 84-85).

E ele fecha o seu texto, retomando o diálogo com Lévi-Strauss ao afirmar que, "se quisermos ser capazes de julgar com largueza, como é óbvio que devemos fazer, precisamos tornar-nos capazes de enxergar com largueza" (Geertz, 2001, p. 85). Para então complementar ressaltando que para isso, o que já vimos, isto é, o interior de nossos vagões ferroviários, simplesmente não basta.

Dois autores clássicos da antropologia, Claude Lévi-Strauss e Clifford Geertz, cujas reflexões marcam o debate antropológico contemporâneo sobre cultura e diversidade. Mas como esse debate pode contribuir com as pesquisas sobre interculturalidade e comunicação nas organizações? É o que exponho nas considerações finais, a seguir. 


\section{CONSIDERAÇÕES FINAIS}

Discorro aqui sobre algumas contribuições que os debates antropológicos contemporâneos em torno do conceito de cultura e da ideia de diversidade podem trazer para fertilizar a pesquisa sobre comunicação e interculturalidade nas organizações.

A primeira dessas contribuições tem a ver com a desestabilização da cultura. Sim, a cultura é uma face central da experiência humana, associada à nossa capacidade de simbolizar. De fato, como nos lembra Sahlins (1997a), nenhum outro animal distingue água de água benta, pois no plano químico não existe diferença alguma. Elas se diferenciam à medida que a água benta está embebida em um significado compartilhado pelos representantes de certa comunidade religiosa. Porém, a cultura não é homogênea, mas sim marcada por descontinuidades, contradições e conflitos. Não é igualmente uma entidade autocontida, sendo elaborada e reelaborada nos processos de empréstimos, de troca. Para pensarmos a comunicação intercultural nas organizações é necessário ter isso em mente.

Como bem destacam Akhil Gupta e James Ferguson (1999), a questão que se coloca para os pesquisadores da cultura é entender a comunicação não dentro de um mundo social e economicamente compartilhado, mas por meio das culturas e entre sociedades. E, para tanto, aqueles que, seja por infortúnio da vida, seja por dever de ofício, vivem cruzando as fronteiras culturais, como os imigrantes refugiados ou a elite profissional das corporações transnacionais, certamente são sujeitos de pesquisa privilegiados. Mas esses sujeitos não se encontram num vácuo político. Suas relações são marcadas por disputas, por jogos de poder. As práticas culturais não possuem o mesmo status. Elas têm distintos pesos e algumas são não apenas estereotipadas, como costuma acontecer nos encontros interculturais, mas também fixadas como exóticas.

É preciso ter em mente também que a diversidade, essa riqueza da humanidade, pode ser observada não apenas quando indivíduos de diferentes sociedades ou organizações se encontram. Se a cultura não deve ser vista de maneira homogênea, então é preciso lembrar a cada pesquisa que as culturas nacionais e as culturas organizacionais são ficções, são narrativas construídas para tentar dar um sentido de unidade à nação ou à organização. Porém, os produtos da ação humana são sempre polissêmicos; o sentido deve ser sempre pensado no plural, na tensão entre os distintos significados que nações e organizações possuem para os seus membros e para aqueles que interagem com elas. No entanto, não devemos esquecer que, para além das nossas diferenças linguísticas, culturais, organizacionais; existe irremediavelmente algo que potencialmente nos assemelha. Como bem apontou Appadurai (2003), há sempre uma diferença numa identidade e uma identidade numa diferença. Assim, sujeitos subalternizados em diferentes culturas nacionais e/ou organizacionais (como negros, mulheres, LGBTs, ou membros de outros grupos minorizados), por exemplo, podem se reconhecer em seus encontros interculturais nas organizações, a despeito das diferenças entre suas culturas de origem.

Em síntese, o que pretendo deixar aqui, como uma mensagem que, espero, possa fertilizar as pesquisas sobre comunicação e interculturalidade nas organizações, é a advertência para que não tomemos nem a cultura, nem tampouco as organizações como algo evidente. Não existem culturas nem organizações já prontas que se encontram na comunicação que se estabelece entre os seus membros. Existem, sim, culturas e organizações que se modelam e remodelam nesses encontros. Indivíduos que se constituem nos trânsitos que fazem entre as culturas e as organizações. Aqui podemos relembrar a advertência que fez ao "caminante" o escritor António Machado. "No hay camino, se hace camino al andar", disse ele. Recupero sua frase, para acrescentar outra que teci ao cruzar leituras antropológicas com um diálogo imaginário com o poeta sevilhano. Uma frase com a qual tenho brincado ultimamente: "tampouco hay caminante, el caminante se hace en el camino". 
E quanto aos amigos estrangeiros aos quais fiz referência no início deste artigo? Eles, que estão planejando ter filhos, já se questionam como irão educá-los no plano linguístico. Luca não abre mão de que os filhos falem italiano e quiçá napolitano, já que pretende passar para eles parte das tradições que recebeu da sua criação em Nápoles. Andra, por sua vez, deseja fortemente que falem romeno, para não perderem os vínculos familiares, para conhecerem parte de sua história. As crianças, que crescerão na França, se verão atravessadas de saída por quatro diferentes línguas (italiano, napolitano, romeno, francês), que são também distintos repertórios culturais. Isso para não mencionar o inglês, língua franca da comunicação no mundo global; e o mandarim, cuja utilização cresce com a ampliação da importância da sociedade chinesa na globalização. E nos caminhos por onde passarem, ao andarem pelas estradas da vida, enquanto se constroem ao caminhar, poderão acrescentar outras línguas, outras culturas. Serão, mais ainda que seus pais, pessoas cujas experiências sociais serão desenhadas in-between cultures. E certamente terão muito a ensinar àqueles que querem compreender questões relativas à interculturalidade e à comunicação, dentro e fora das organizações.

\section{REFERÊNCIAS}

ABU-LUGHOD, Lila. Writing against culture. In: FOX, Richard (Ed.). Recapturing anthropology. working in the present. Santa Fe: School for American Research Press, 1991.

APPADURAI, Arjum. Modernity at large cultural dimensions of globalization. Minnesota, MN: The University of Minnesota Press, 2003.

BAKHTIN, Mikhail. Marxismo e filosofia da linguagem. São Paulo: Hucitec, 2004.

BARTH, Fredrik. A análise da cultura nas sociedades complexas. In: BARTH, Fredrik. 0 guru, o iniciador e outras variações antropológicas. Rio de Janeiro: Contra Capa, 2000.

BENEDICT, Ruth. Padrões de cultura. Lisboa: Livros do Brasil, 1978.

CLIFFORD, James. Introducción: verdades parciales. In: CLIFFORD, James; MARCUS, George (Ed.) Retóricas de la antropología. Barcelona: Jucar Universidad, 1991.

Sobre a autoridade etnográfica. In: CLIFFORD, James. A experiência etnográfica: antropologia e literatura no século XX. Rio de Janeiro: Ed. UFRJ, 1998.

EAGLETON, Terry. A ideia de cultura. São Paulo: Ed. Unesp, 2005.

GEERTZ, Clifford. A interpretação das culturas. Rio de Janeiro: Guanabara-Koogan, 1989.

. Os usos da diversidade. In: Nova luz sobre a antropologia. Rio de Janeiro: Jorge Zahar, 2001.

GUPTA, Akhil; FERGUSON, James. Beyond "culture": space, identity and the politics of difference. In: Culture, power, place: explorations in critical anthropology. Durham and London: Duke University Press, 1997. 
HALL, Stuart. Quem precisa da identidade? In: SILVA, Tomaz Tadeu (Org.). Identidade e diferença: a perspectiva dos estudos culturais. Petrópolis: Vozes, 2000.

HANNERZ, Ulf. Cultural complexity. studies in the social organization of meaning. New York: Columbia University Press, 1992.

Cuando la cultura está en todas partes: reflexiones sobre un concepto favorito. In: HANNERZ, Ulf. Conexiones transnacionales. cultura, gente, lugares. Madrid: Cátedra, 1998.

. Diversity is our business. In: Anthropology's world. life in a twenty-first-century discipline. New York: Pluto Press, 2010.

KESSING, Roger. Anthroplogy as interpretive quest. Current Anthropology, v. 28, n. 2, 1987.

KUPER, Adam. Cultura: a visão dos antropólogos. Bauru: Edusc, 2002.

LÉVI-STRAUSS, Claude. O olhar distanciado. Lisboa: Edições 70, 1986.

Raça e história. In: Antropologia estrutural dois. Rio de Janeiro: Tempo Brasileiro, 1993.

MAYA, Nomy. What we talk about when we talk about culture. American Anthropologist, v. 103, n. 2, p. 432-446, 2001.

ORTNER, Sherry et al. Introduction. In: ORTNER, Sherry et al (Ed.) Culture, power, history. a reader in contemporary social theory. Princeton, NJ: Princeton University Press, 1994.

ROSALDO, Renato. Culture and truth: the remaking of social analysis. Boston, MA: Beacon Press, 1993.

SAHLINS, Marshall. 0 "pessimismo sentimental" e a experiência etnográfica: por que a cultura não é um "objeto" em via de extinção. Parte I. Mana - Estudos de Antropologia Social, v. 3, n. 1, p. 41-73, 1997 a.

. 0 "pessimismo sentimental" e a experiência etnográfica: por que a cultura não é um "objeto" em via de extinção. Parte II. Mana-Estudos de Antropologia Social, v. 3, n. 2, p. 103-150, 1997 b.

WOLF, Eric. Encarando o poder: velhos insights, novas questões. In: FELDMAN-BIANCO, Bela; RIBEIRO, Gustavo Lins (Org.) Antropologia e poder: contribuições de Eric Wolf. Brasília: UnB; São Paulo: Imprensa Oficial; Campinas, Editora da Unicamp, 2003.

Artigo recebido em 20.08.2014 e aprovado em 25.09.2014. 